\title{
Familial transmission of human longevity: a population-based study in an inland village of Sardinia (Italy), 1850-2010
}

\author{
Luisa Salaris, Nicola Tedesco and Michel Poulain*
}

\begin{abstract}
This study investigates the role of familial transmission on individual survival in an inland community of Sardinia that stands for the exceptional longevity of its inhabitants. The analysis considers the complete survival trajectories of individuals born in the village of Villagrande Strisaili from unions in the period from 1850 to 1910 and aims to estimate the possible effect on the relationships parent-offspring and between siblings. Our results show that the frail familial component of the population, rather than the robust one, proves to be a good predictor of individual survival. No association between father survival and that of children was found. Having instead a long-living mother increases lifespan, especially for daughters. But the strongest relationship is that observed between siblings. The survival of siblings is positively associated with individual survival and this relationship is particularly strong for males. This finding points for both genetic and environment influence, and particularly of early-life conditions, on longevity.
\end{abstract}

\section{Introduction}

Human longevity is complex and numerous studies conducted up to the present time have shown that there is not a single straightforward explanation for longer survival but that several factors must be taken into account when examining longevity. Within the eligible determinants used to explain longer survival, family characteristics have proved to play a relevant role, both in terms of inherited genetic traits and of a common shared environment.

\footnotetext{
${ }^{*}$ Luisa Salaris (correspondance author), DISSI - Dep. Social Sciences and of Institutions, University of Cagliari, Italy. Email: salaris@ unica.it

Nicola Tedesco, DISSI - Dep. Social Sciences and of Institutions, University of Cagliari, Italy.

Michel Poulain, Estonian Institute for Population Studies, Tallinn University, Estonia; IACCHOS, Université catholique de Louvain, Belgium.
} 
Since the last century, with the work of Beeton and Pearson (1899; 1901), the inheritability of longevity has been the subject of several studies which focused on the analysis of genealogical records (Jalavisto 1951; Gudmundsson et al. 2000; Westendorp and Kirkwood 2001; Gavrilov and Gavrilova 2001; Mitchell et al. 2001; Kerber et al. 2001; Garibotti et al. 2006) or on selected population subgroups such as twins (McGue et al. 1993; Herskind et al. 1996; Ljungquist et al. 1998; Iachine et al. 1998) and centenarians (Poulain et al. 1998; Perls et al. 2002, 2007; Willcox et al. 2006; Gavrilov and Gavrilova 2011; Jarry et al. 2012a, 2012b), as well as on the possible relationship between parents, siblings and spouse with respect to successful ageing (Frederiksen et al. 2002; Gionça and Zaninotto 2008; Liu et al. 2011) and survival (Bocquet-Appel and Jacobi 1990; Dejardins and Charbonneau 1990; Cournil et al. 2000; Blackburn et al. 2004; Mazan and Gagnon 2007; You et al. 2010).

The use of reconstructed family databases collected by researchers in biodemography and by historical demographers represents an alternative approach to pure genetic analysis in the investigation of the role of the familial component for survival, although demographic data lead to indicative and non-conclusive results.

The aim of this contribution is an in-depth study of the role of familial transmission on individual survival through the use of historical data of an inland village of Sardinia-Villagrande Strisaili, which has been documented as a particularly longliving community (Poulain et al. 2004; Salaris 2010; Poulain et al. 2011). Prior work carried out in the same village by Salaris (2010) on the possible role of family characteristics on individual survival that used a fixed longevity threshold could show that maternal age at death predicted higher survival and, more importantly, that having at least one sibling that reached 90 years proved to influence longevity. Previously, a study on a selected number of Sardinian centenarians' pedigrees conducted by Caselli et al. (2006) had stressed the existence of a familial component in Sardinian longevity, in most cases originating from the maternal side.

The present study considers the survival trajectories of individuals born in the village of Villagrande Strisaili from marriages in the period from 1850 to 1910. While Salaris's previous study (2010) took into account statistics from 1866-the year of the institution of civil status registers - this analysis is extended back to the period before 1866, thanks to information gathered from parish registers. By adopting a longitudinal perspective, each individual is followed from birth to death. The relationship between age at death of parents (mother and father) and of siblings is investigated here by adopting relative longevity thresholds that take into account the general level of survival of the population. These thresholds led to the identification of groups of survivors classified as frail, normal and robust.

The decision to conduct a population-based study for the village of Villagrande Strisaili was driven by the need to gather information not only on single individuals but also on all family links. To avoid bias due to incompleteness or selection of subjects, all family members are included in the initial database who were alive at the time of the study in the village, including those who later died young. The population under study was then reduced to a clearly identified group of individuals, starting 
from all individuals born from marriages concluded between 1850-1910, and later focusing on 50-year-old survivors.

Studying a single setting limits the effect that differences at individual level in both physical environment and culture could have on survival estimates. Since individuals share the same geographical space they are assumed to be exposed to the same environmental and cultural conditions. Therefore, this approach makes it possible to investigate the role of familial variables while controlling for most community variables.

The present contribution focuses on the estimation of possible effects on the relationships parent-offspring and between siblings in a population such as that of Villagrande Strisaili which, as mentioned earlier, has proved to be particularly longliving (Poulain et al. 2004). According to the indications derived from prior research (Christensen et al. 2006) and in order to measure the effect of genetic endowment as well as to exclude from the investigation the influence of early and accidental deaths, the analysis focuses on the survival, after age fifty, of persons born in the selected village. By means of survival analysis the study looks at the relationship between age at death of an individual and that of his/her father and mother, as well as that of any siblings, and devotes particular attention to sex and birth cohort differences.

\section{Data and methods}

\subsection{Data sources and data quality}

The data for this study were mainly obtained from civil status registers introduced in 1866 in all municipalities of the newly unified nation of Italy, and from reports of all vital events (birth, marriage, death) occurring in the municipality (Del Panta and Rettaroli 1994). To gather information on demographic events occurring before 1866, data collection has also included parish registers, which are available for Villagrande Strisaili since 1633 (Anatra and Puggioni 1983). These latter registers and the population registers (i.e. anagrafe) were systematically used to crosscheck information reported in vital statistics. Data were collected at individual level.

Through the analysis of birth, marriage and death acts, the survival trajectory of each individual was followed from birth to death. This procedure of individual linkage between different demographic events allowed for a rigorous validation of data used. Possible cases of under-registration of births and related deaths, effects of selective migration, age misreporting at older ages and problematic linkages were carefully considered in order to ensure high-quality data.

\subsection{Population under study}

The municipality of Villagrande Strisaili is one of the 14 municipalities identified in the Blue Zone of longevity in inland areas of Sardinia (Poulain et al. 2004). 
The population under study was selected starting from all marriages that took place in the village of Villagrande Strisaili from 1850 to 1910, which were 444 in total. In summary, 2,306 children were born from these unions, recording an average of 5.2 children per family. Data collection covered the period from 1850 to 2010 and provides a level of coverage of 94.4 per cent of known survival for 2,306 individuals included in the database.

Based on the indications derived from prior research on longevity (Christensen et al. 2006), we decided to focus on post-reproductive survival, namely on 50-yearold individuals (1.018 cases). In this manner, the effect of early deaths (infant and child mortality) as well as accidental deaths could be excluded from the analysis. The distribution of 50+ survivors approximates a normal curve (Cournil et al. 2000), individuals can die almost exclusively from causes related to the ageing process which facilitates the exploration of possible genetic effects, despite the fact that early-life conditions and shared environment have persistent effects at old age.

Only children (i.e. people having no siblings) and individuals who appeared to be the sole survivors to 50 years of the family of origin were excluded from the analysis. Therefore, the study of survival resemblance was restricted to all individuals for whom ages at death of both father and mother were known and who had siblings surviving at 50 years old and over (874 cases).

The exclusion of a limited number of cases, because of only partially available information, from the original group of survivors aged 50+, results in the reduction of the number of examined cases to 874 . This in turn may create a phenomenon of survival selectivity. The 174 individuals excluded are distributed as follows: 87 cases (50\%) with incomplete information on both parents' survival; 77 cases (44\%) that had no siblings surviving to age 50 and over; 10 cases $(6 \%)$ of only children. Differences in survival curves were therefore tested for significance, both considering all individuals (Breslow chi square $=1.444$, p-value $=0.486$; log-rank chi square $=1.026$, $\mathrm{p}$-value $=0.599$ ) and separately by sex (for females: Breslow chi square $=0.556, \mathrm{p}$-value $=0.757 ;$ log-rank chi square $=0.684, \mathrm{p}$-value $=0.710 ;$ for males: Breslow chi square $=0.983$, p-value $=0.612 ; \log$-rank chi square $=0.405$, $\mathrm{p}$-value $=0.817$ ). The excluded cases were equally distributed over all ages and this implied no significant differences from the initial database and no introduction of sex biases as confirmed by sensitivity test scores.

Differences in the mean age at death of individuals under study, of father, mother and siblings, were also checked and calculated separately for the initial database and the final subpopulation used for the analysis. No impact whatsoever on average survival estimates was noted.

\subsection{Demographic variable for analysis}

The goal of the study is to investigate family transmission of longevity, therefore the focus is on the relation between individual survival and that of parents (father 
and mother) and of siblings, with particular attention devoted to sex and birth cohort differences.

Age at death of father, mother and siblings has been specified as categorical variables in preliminary exploration of the data, namely in comparison of means and Kaplan-Meier survival curves, and as a continuous variable in Cox proportional hazard models thereafter.

As in prior works the choice of a fixed survival threshold has proved to greatly influence the observed hereditary effects of parental survival on that of their offspring (Cournil et al. 2000), the survival experiences of parents and siblings were operationalised here through the creation of a variable based on a relative longevity threshold according to the distribution of deaths and their cumulative percentage.

Long-living fathers, mothers and siblings were identified in the eightieth percentile and above as proposed by Blackburn et al. (2004), taking into account in this way those individuals that survived longer compared to the general population level. ${ }^{1}$ This group has been denominated here as 'robust'. In order to consider the presence of different groups of survivors other than the robust ones, two additional groups were identified in this study. In a similar way but in opposition to the robust, in the twentieth percentile and below of the distribution of deaths, individuals less fit for survival were classified as 'frail'. All other survivors were considered as 'normal'.

With regard to the thresholds of relative ages for identifying the 'robust' and 'frail' parents and siblings, the relative survival threshold for 'frails' was identified for females at 57.9 years (father), 55.3 years (mother) and 75.1 (siblings); and for males at 56.9 years (father), 56.3 (mother) and 73.0 (siblings). With regard to the 'robust' group of survivors, the longevity threshold for females corresponded to 83.3 years (father), 83.6 years (mother) and 86.8 years (siblings); while for males it was 83.6 years (father), 83.3 years (mother) and 86.2 years (siblings).

The use of survival categories has been instrumental for early data exploration, since it is known that historical time has an impact in the distribution of age at death (i.e. cohort effect). This limitation disappears in the Cox models, where all survival variables are considered as continuous and the effect of changing historical conditions is included in the model by controlling the estimates for the birth cohort of the individuals and of both parents.

The average age at death of siblings deserves further clarification. What was mentioned above with regard to the identification of survival groups is true for the average age at death of sibship excluding the individual in focus (as proposed by Mazan and Gagnon 2007) and this measure is used hereafter to investigate differences in mean survival and Kaplan-Meier estimation. The use of this average allows us to

1 Right-truncated cases represent $2.6 \%$ of the population under study, which were included in the analysis considering their survival up to truncation time. Only $0.5 \%$ of the sample had its censoring time before age 80 and $1.2 \%$ of censored cases are represented by still-living individuals. 
assign a value to each individual which summarises the survival experience of the sibship aged 50 and over.

In the Cox models it was decided, however, to weigh the average age at death of siblings previously calculated by the proportion of survivors belonging to the eightieth percentile and over (longevity threshold at 90.1 years), excluding also in this case the age at death of the individual in focus from the calculations. The classification as to robust or not robust was carried out on the basis of age at death of individuals and the weight was determined by the proportion of individuals over the eightieth percentile compared to the total number of 50-year-olds and over in the same family. This weighting system was constructed to take into account the fact that any episodes of marked longevity might be repeated in many individuals within the same family. Weight therefore strengthens the membership of individuals of possibly robust families. This measure, however, does not allow us to distinguish between genetic and environmental components.

Finally, family groups were identified and coded with a unique four-digit number assigned to each family to allow the introduction of family-shared frailty based on survival of all siblings (including the individual in focus) in the extended Cox proportional hazard model. All three proposed measures of average sibling survival (average age at death of siblings excluding ego, weighted average at death of siblings, and shared sibship frailty) were considered alternatively in the Cox proportional hazard model fit.

\subsection{Methods}

The initial exploration of the data was performed by sex and by average survival of individuals according to their familial longevity group (i.e. frail, normal, robust fathers, mothers and siblings). Differences were tested for significance. To improve the understanding of the possible relationship between the survival of family members and that of the individual in focus in a longitudinal perspective, the analysis was further developed using a non-parametric approach, namely the Kaplan-Meier survival estimation (Kleinbaum 1995). Differences within categories were tested for significance by means of Breslow and Log Rank tests (Blossfeld and Rohwer 2002).

Finally, a series of Cox models were fit to assess whether other family members' survival could be deemed a good predictor of the individual lifespan. Model 1 considers all covariates without any specification or stratification. In Model 2 the estimates are controlled for the effect of birth cohort of ego and that of his/her father and mother, thus taking into account the role of secular improvements in survival. Sibling survival here considers the average age at death of siblings as proposed by Mazan and Gagnon (2007).

Given the relevance attributed in prior research to sibling survival as a powerful predictor of individual lifespan, Model 3 investigates the effect of siblings' survival, this time weighting their average age at death by the proportion of survivors at the eightieth percentile and above, considering the concept of robustness in each family. 
Due to the importance of possible sex differences in parent-offspring transmission of longevity, Model 2 and Model 3 were run separately for males and for females.

Finally, Model 4 attempts to examine the relationship between siblings' survival simultaneously, moving from a traditional Cox model to an extended one (Therneau and Grambsch 2000) by introducing into the model family-shared frailty, which considers the survival of all siblings including the individual in focus. As reported by Fan and Li (2002:80) "frailty corresponds to a random block effect that acts multiplicatively on the hazard rates of all subjects in a group". In our case the group is represented by the family, whose members share both genetic and environmental influences on longevity. Shared frailty aims at accounting for unobserved factors affecting an individual's risk of mortality which are assumed to be equally shared with others in the family (Wienke 2003; Garibotti et al. 2006). Shared frailty is here assumed to be gamma-distributed (Therneau and Grambsch 2000). All the covariates included in the Cox models met the proportionality assumption which was tested using Schoenfeld residuals (1982).

\section{Results}

\subsection{Parental transmission and survival resemblance of siblings}

From the analysis of the distribution of age at death and of average values it emerges that there are no significant differences by sex between Villagrande Strisaili 50-yearold individuals as the mean age at death for females is 79.8 years (max. 107.9 years), while for males it is 79.9 years (max. 104.9 years).

Figure 1 shows that males and females in Villagrande Strisaili follow similar mortality patterns and the greater proportion of deaths for both sexes occurs from age 75 to age 94 and the modal age group is observed at $85-89$ years old.

When we shift attention to the distribution of death among parents, we observe that parents record lower mean survival: 69.0 years for mothers [min. 22-max. 98] and 69.8 years for fathers [min. 32-max. 100] when considering them all; and 74.7 years for mothers and 73.2 years for fathers when the analysis is limited to parents surviving 50 years and over. From this preliminary data, focusing only on survivors 50 years old and over (Figure 1), we observe a difference of an average of 5-6 years between the generation of at least 50-year-old parents and that of their offspring, suggesting that we are facing a change in the average age of survival due to improved living conditions between the two generations. The values of average age at death of parents 50-year-old and over are coherent with the estimates reported in Table 1 for individuals, both males and females, belonging to older birth cohorts.

Accordingly, and considering in addition the results of subsequent investigations, the role of birth cohort — at individual and parental level—was introduced into the Cox model as a control variable. 


\section{Figure 1:}

Percentage distribution of deaths of 50-year-old parents and offspring according to sex

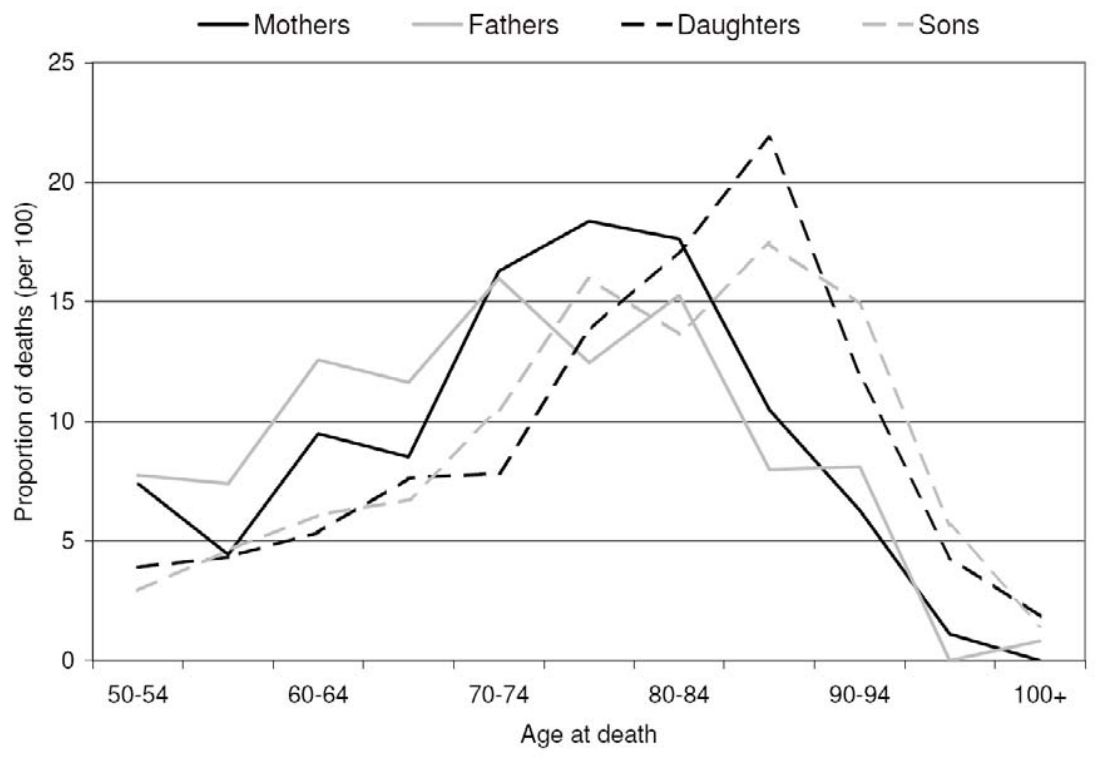

Table 1 reports the average survival for males and females conditional to survival to age 50 by their familial survival group classified according to the distribution of cumulative percentage of death into three groups, as discussed in Section 2.3.

In general, it emerges that the familial survival experience influences longer or shorter survival. If family members have a shorter lifetime, both male and female individuals live shorter lives. 50-year-old children of frail parents live shorter lives than their peers born to robust parents, the only exception being sons of frail fathers, who record a survival advantage of 2.4 years. For all other groups, the differences vary from a minimum of 3.2 years (lower age at death for sons of frail mothers) to a maximum of 4.2 years reduced survival of daughters of frail mothers. Differences between familial survival groups according to parents' survival, however, are not statistically significant.

The importance of the familial component assumes greater significance when the analysis focuses on resemblance within the sibship. Having frail siblings significantly reduces the average survival of the individual by 4.2 years for females and 7.0 years for males. Conversely, if siblings are robust, individuals live longer.

The analysis of survival by birth cohort highlights that in Villagrande Strisaili there is a secular improvement of survival across time and individuals born in more recent cohorts experience higher survival chances; in addition, differences between 
cohorts are statistically significant and females seem to gain greater benefit from the improved living conditions.

\subsection{Kaplan-Meier survival curves}

The use of Kaplan-Meier (KM) curves helps to better understand the evolution of mortality trajectories from age 50 of the identified familial survival groups. The results of sensitivity test scores by sex give a measure of the level of significance of the detected differences, as well as indicating whether they are more relevant at the beginning of the ageing process (Breslow test) or at more advanced ages (log-rank test). For the sake of simplicity, not all survival curves are presented here.

Before discussing in detail what emerges from the comparison of KM survival curves, it is necessary to specify that the tests did not show statistically significant differences between males and females $($ Breslow chi square $=0.014, \mathrm{p}$-value $=$ 0.907 ; log-rank chi square $=0.024$, p-value $=0.876$ )

The adoption of a longitudinal perspective in the data analysis confirms the existence of a cohort effect as well as the importance for a longer survival of not having a family member who died early, as had previously to some extent emerged from the analysis of the differences in the average age at death. ${ }^{2}$ The strong relationship between the survival of siblings is confirmed here especially with regard to the survival experience of males ${ }^{3}$ (Figure 2a and Figure $2 b$ ).

The positive effect of increased maternal lifespan on the survival of individuals of both sexes is supported by statistically significant differences between the survival curves. ${ }^{4}$ As Figure 3a shows, having a long-lived mother significantly affects the survival of daughters from age 65 up to the oldest ages. For males its relevance is detected from 50 years until age 85 (Figure $3 b$ ). In all instances, the greatest differences are observed between the familial group of frail and robust individuals, which means that the other family members' survival experiences could be considered as valuable predictors of individual survival.

\footnotetext{
2 Differences by birth cohort are statistically significant at all ages and for both sexes (females: Breslow chi square $=39.4$, p-value $<0.001 ;$ log-rank chi square $=38.2$, p-value $<0.001 ;$ males: Breslow chi square $=29.0$, p-value $<0.001 ;$ log-rank chi square $=28.8$, p-value $<0.001)$.

3 Both sensitive tests confirm this trend. For females: Breslow chi square $=11.2$, p-value $=0.004$; log-rank chi square $=12.5, \mathrm{p}$-value $=0.002$; for males: Breslow chi square $=17.2, \mathrm{p}$-value $<0.001$, log-rank chi square $=22.0, \mathrm{p}$-value $<0.001$.

4 The paternal survival group is never significant, while the maternal one is particularly significant for females (Breslow chi square $=9.3$, $\mathrm{p}$-value $=0.009$; log-rank chi square $=13.2$, $\mathrm{p}$-value $=0.001$ ); for males we observe instead a slight significance only according to the Breslow test (chi square $=6.2$, p-value $=0.045)$.
} 


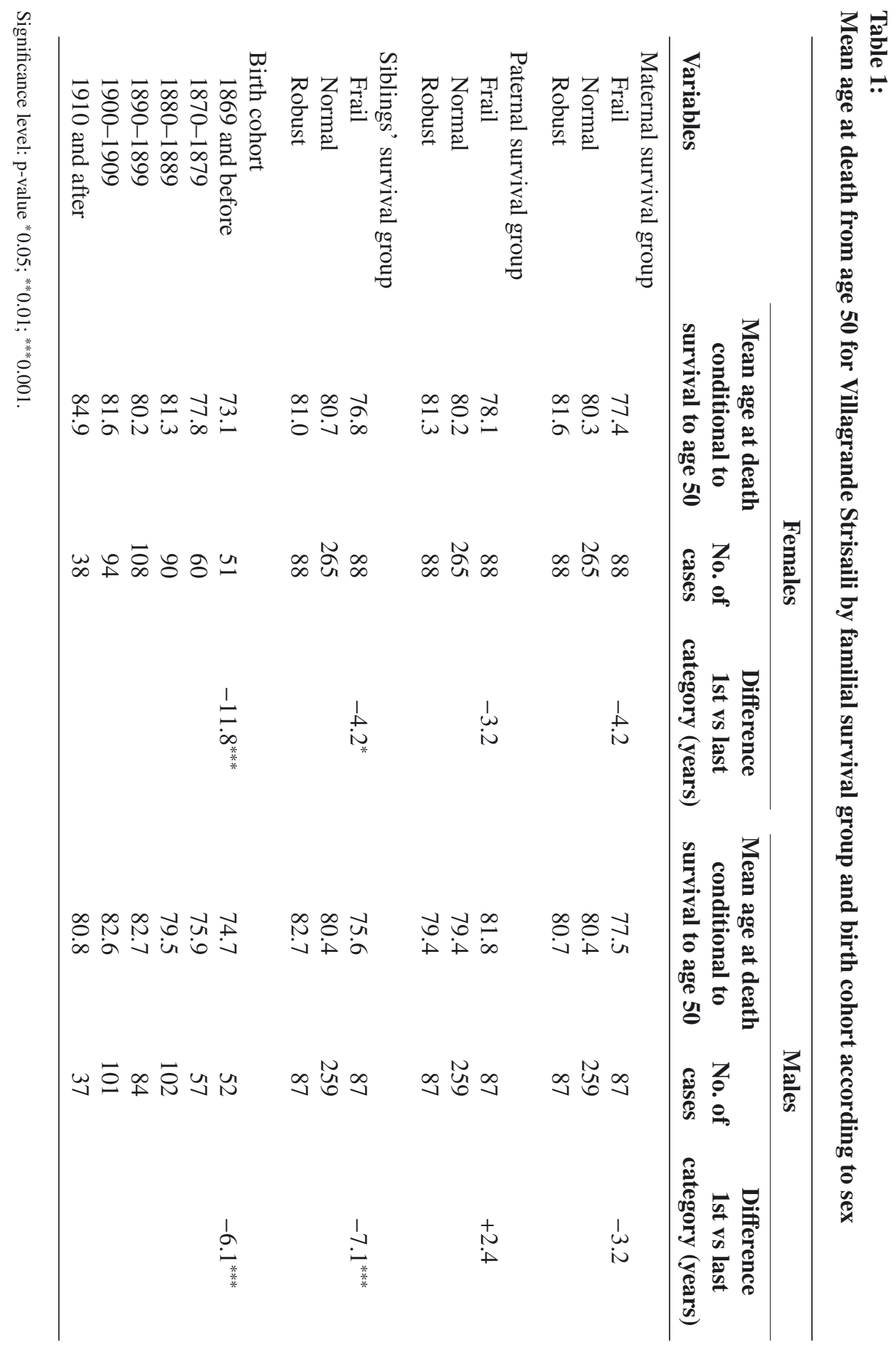


Figure 2:

(a) Kaplan-Meier survival curve from age 50 of Villagrande Strisaili females according to siblings survival group. (b) Kaplan-Meier survival curve from age 50 of Villagrande Strisaili males according to siblings survival group

(a)

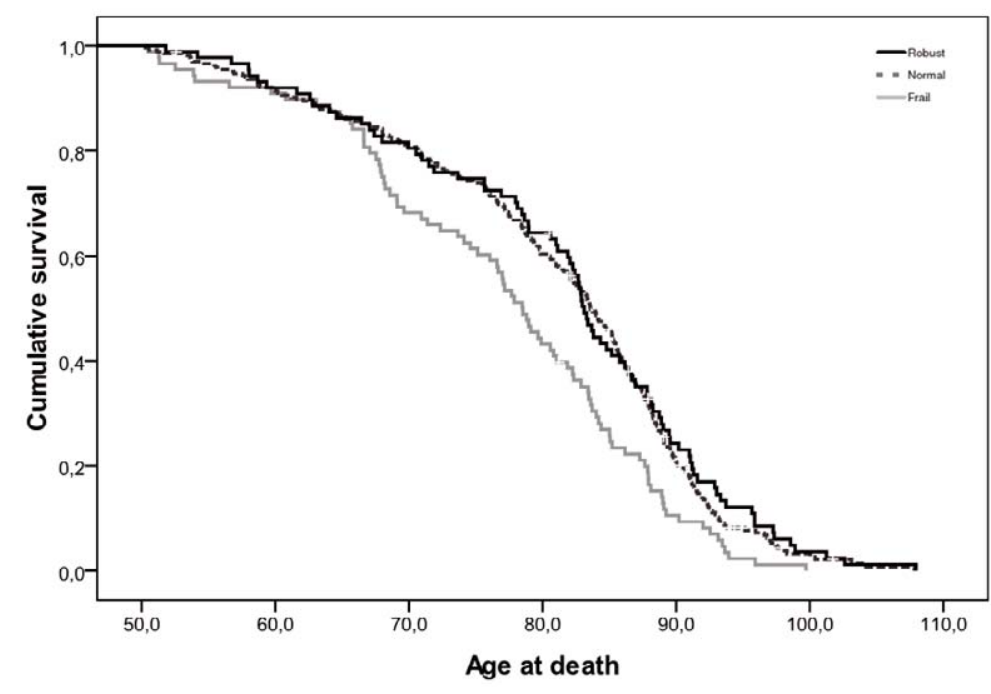

(b)

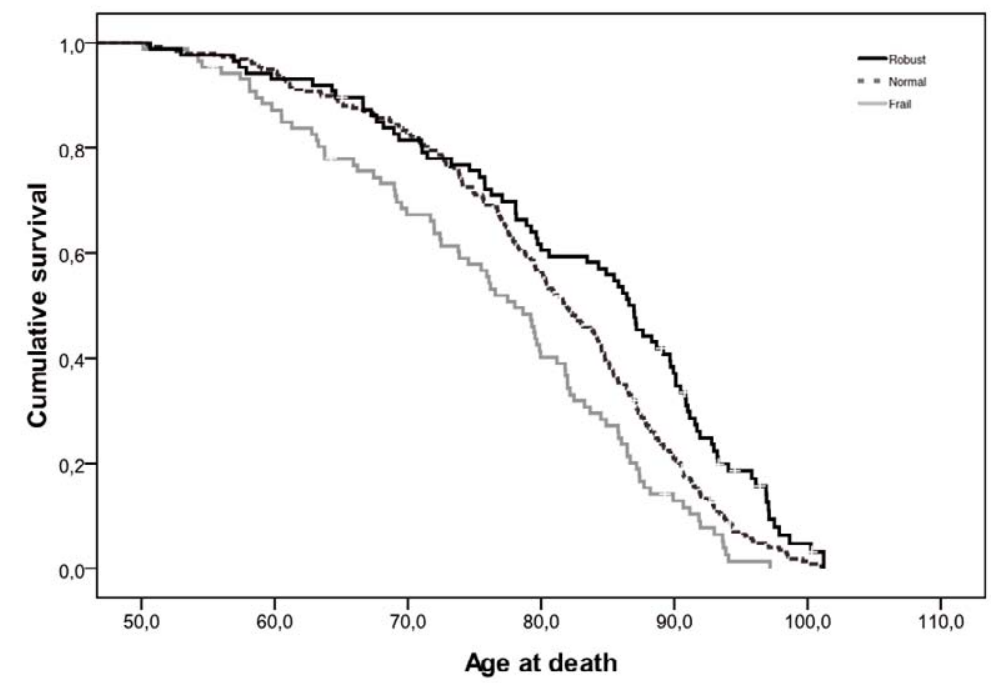


Figure 3:

(a) Kaplan-Meier survival curve from age 50 of Villagrande Strisaili females according to maternal survival group. (b) Kaplan-Meier survival curve from age 50 of Villagrande Strisaili males according to maternal survival group

(a)

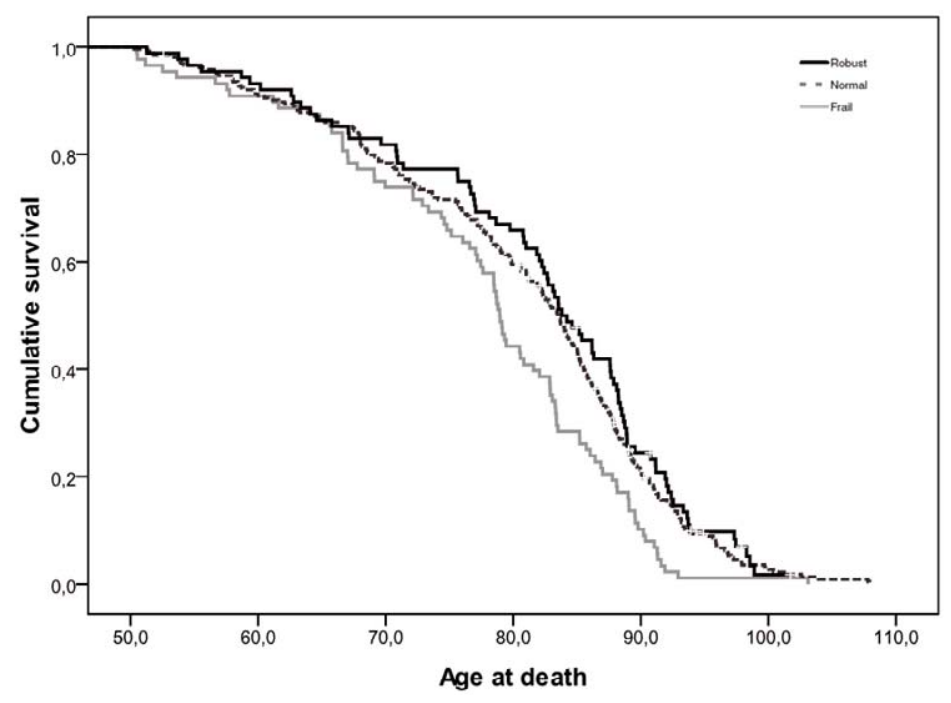

(b)

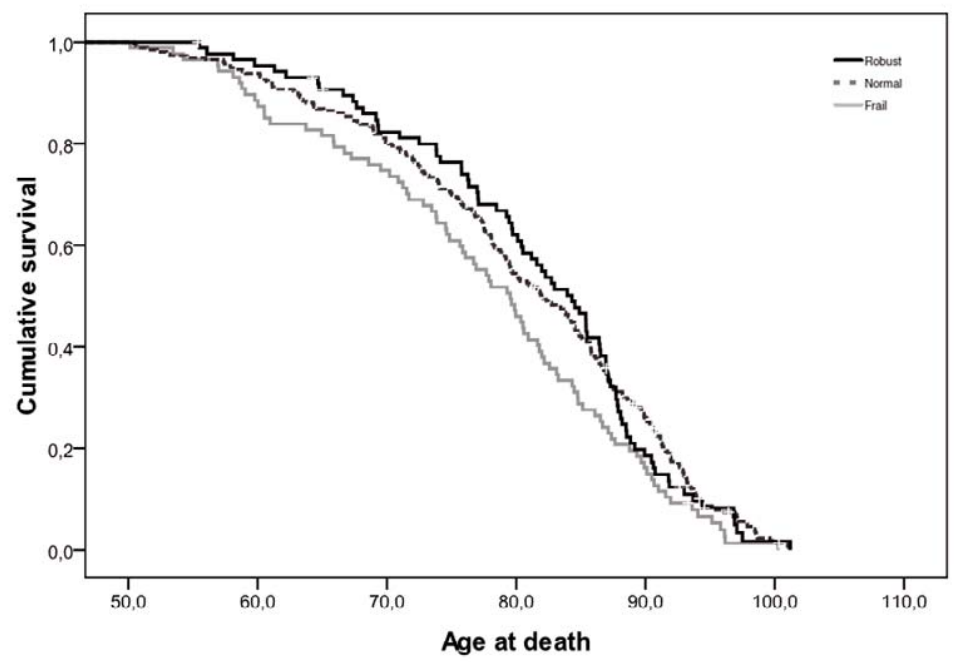




\subsection{Cox proportional hazard models}

As discussed in Section 2.4, a set of Cox proportional hazard models were fit and estimates are presented in Table 2.

All models show that sex has no statistically significant effect on determining individuals' survival differences between males and females, underlying an unusual level of male longevity in the study population. Despite the fact that in developed countries females are expected to live longer than males, this pattern is not observed in Villagrande Strisaili-a peculiarity that has also been examined in prior research carried out in the same village referring to different birth cohorts (Poulain et al. 2004; Salaris 2010; Poulain et al. 2011).

With regard to parent-offspring relationships, maternal age at death proves to be relevant and its importance persists in all models. To investigate the different impact of the mother's age at death on individual survival, Model 2 has been run separately for males and females. As shown in Table 3, among the possible relationships between parent and offspring survival, the only one worthy of note is the mother-daughter one (odds ratio $=0.992$ ), which suggests that transmission seems to be same-sex linked.

The most important relationship among family members is that between siblings, which is highly significant and-when Model 2 is run separately for the two sexesproves to influence male survival slightly more importantly (odds ratio $=0.980$ ) than female survival (odds ratio $=0.984$ ). This difference in sibling survival resemblance for males confirms the findings of preliminary exploration of the data both in average comparison and by means of KM survival curves.

When in Model 3 the average survival of siblings is weighted for the proportion of survivors at the eightieth percentile and above over 50+ survivors of each family, the sibling survival effect remains highly significant (odds ratio $=0.972$ ).

The introduction of family-shared frailty in the Cox model (Model 4) allows us to detect the presence of unobserved family covariates that significantly influence survival after 50 years. In Model 4 the effect of siblings' longevity is no longer estimated by their average survival but is based on age at death of individuals within each family group. The inclusion of sibship frailty in Model 4 implies reasoning in group terms as it expresses the common susceptibility to death exhibited by all siblings in the family. The sibship frailty is moderately significant ( $\mathrm{p}$-value $=0.046$; variance of random effect $=0.0669$ ). This suggests that a family frailty component exists with regard to mothers' age at death. However, the high level of longevity that characterises the population examined, together with the substantial absence of gender differences, is not likely to allow for the observation of a markedly significant effect in our sub-population. It cannot be stated whether the detected frailty is significantly determined by genetic or environmental variables. 


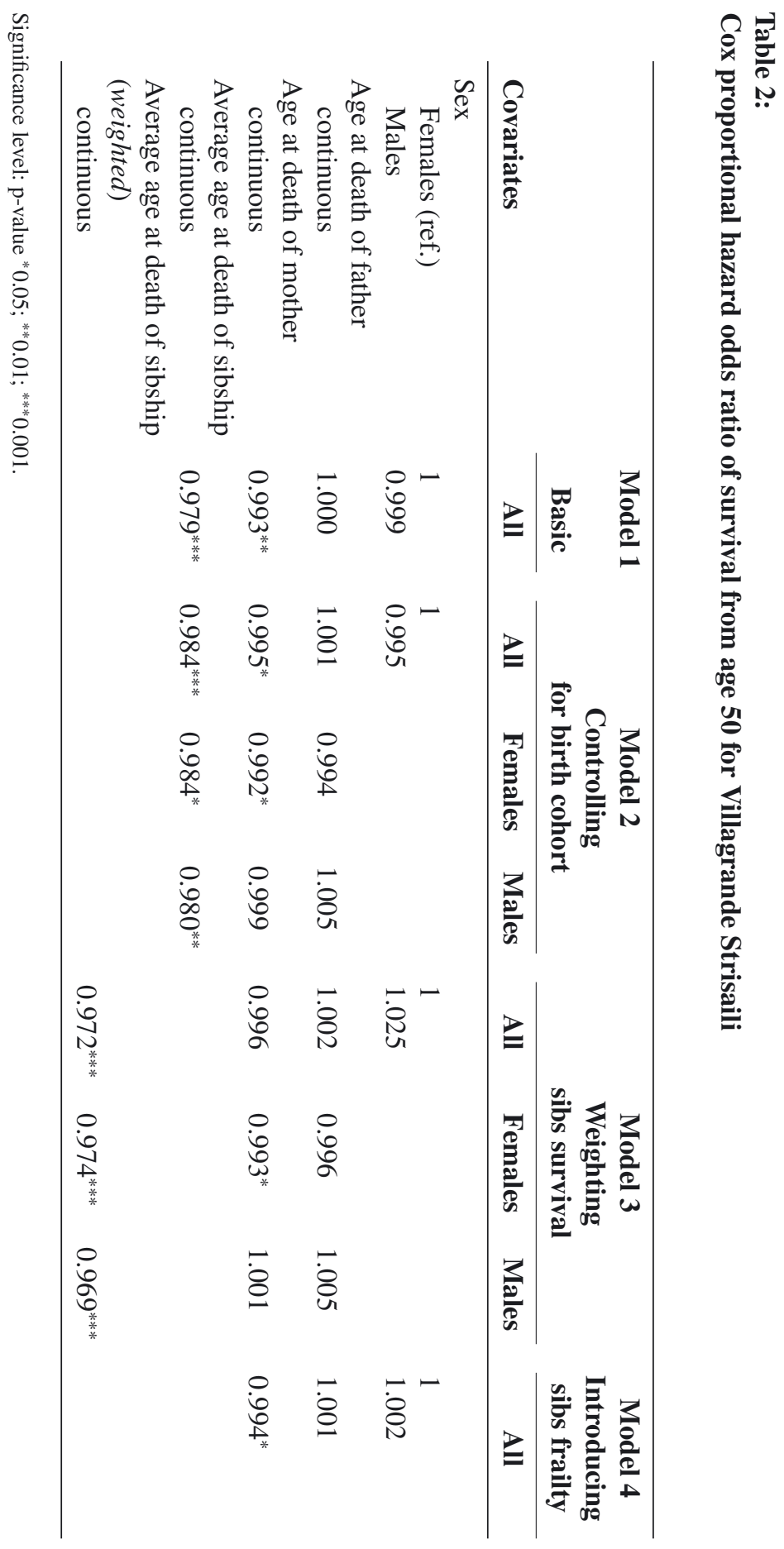




\section{Discussion}

The results presented show that even in a community such as Villagrande Strisaili, which stands out for the exceptional longevity of its inhabitants, family factors do influence longer survival. Among the most significant aspects, we confirm that we are dealing with a community where there are no statistically significant differences between male and female survival. The examination conducted of the relationship parents-offspring and between siblings reveals that the latter relationship turns out to be particularly important. All relevant factors are discussed in greater detail in the following sub-sections, where we attempt to identify points of convergence and peculiar features with other studies on family survival relationship which focused on different populations.

\subsection{No sex survival differences in Villagrande Strisaili}

As evidenced by an earlier study on the population of Villagrande Strisaili that analysed longitudinally the survival of cohorts 1872-1912 (Poulain et al. 2011), in the present work (which has extended back the period to earlier birth cohorts) no statistically significant sex differences in survival were observed. The absence of sex differences obviously has an impact on analysis estimates and particularly on the frailty model since within family groups it makes it difficult for the model to distinguish families according to the possible different gender compositions.

As shown in Figure 1, males and females present similar mortality patterns. Significant differences between them do not emerge in the longitudinal perspective. How to explain this phenomenon? In general, the sex differential in survival is attributed to inequality in the occurrence of certain medical disorders such as cardiovascular diseases, lung cancer and also accidents, which are more frequent among males (Gionça et al. 1999; Guralnik et al. 2000; Austad 2006). Among the relevant factors, a healthy lifestyle during the early elderly years proved to enhance male survival and improve health and function in older age (Yates et al. 2008).

In the case of Sardinia, the low level of mortality due to cardiovascular diseases at 80 years and over was detected as a possible explanation for the differences in sex ratio value observed at more advanced ages (Caselli and Lipsi 2006).

Poulain et al. (2011) who examined the case of Villagrande Strisaili did not identify a single factor responsible for the non-existing survival differences between the two sexes, but the authors emphasised the possible role played by biological/genetic factors such as telomere length (Aviv et al. 2005) and mitochondrial DNA (Fraumene et al. 2003), while behavioural and sociocultural factors were assumed to have influenced gender differences in social roles (Assmuth 1997), in lifestyle and nutrition, physical activities and energy balance (Pes et al. 2013). 


\subsection{Transmission of longevity: the role of parental survival on the offspring}

The survival experience of parents is associated with the lifespan of their offspring. In Villagrande Strisaili we observe that individuals born to long-lived mothers and fathers live longer on average than their peers born to frailer parents. However, paternal and maternal survival acts differently on individual survival with variable effects on males and females.

In the examined population the relationship between the survival of the father and that of his offspring is quasi-absent in all analyses and it is worth reflecting on this puzzling result. As we had the opportunity to underline the results of the comparison of mean age at death by familial survival group (Table 1), we observed that 50-year-old males born to robust fathers live shorter lives than their peers born to frail ones. The set of Cox models presented in Table 3 confirm this trend, namely that the increase in the age of the father at death has a reducing effect on male offspring survival. How to explain this result? Since estimates are not statistically significant, it is difficult to speculate on the possible reasons for the pattern observed.

According to the findings of other studies, the role of the paternal effect on offspring survival is not really clear and varies depending on the examined populations. Some studies in fact found a positive association between fathers and their offspring (Gavrilov and Gavrilova 2001) and particularly an important fatherdaughter relationship at advanced ages (Poulain et al. 1998; Cournil et al. 2000; Gavrilov and Gavrilova 2001; Blackburn et al. 2004), while others reported no statistically significant effect of paternal survival (Jalavisto 1951; Matthijs et al. 2002; Mazan and Gagnon 2007). In general, findings on paternal effect are different, divergent and inconclusive; probably because the relationship is more complex than we assume. Furthermore, we should not neglect the effect that the longevity threshold adopted in the different studies has on the estimates.

Maternal association on the other hand proves to be of greater importance than paternal association in Villagrande Strisaili. The mother's age at death turns out to be a significant predictor of individual survival and this relationship emerges when a longitudinal perspective is adopted. The positive effect of having a long-living mother is particularly relevant for daughters, emphasising the greater relevance of the mother-daughter transmission line.

This finding is consistent with prior investigation on the role of familial transmission among Sardinian centenarians, which examined a limited number of family trees and suggested that clustering of exceptional survival was mainly on the maternal side (Caselli et al. 2006). A greater maternal effect was observed in other populations as well (Jalavisto 1951; Desjardins and Charbonneau 1990; Westendorp and Kirkwood 2001; Blackburn et al. 2004).

From a genetic point of view, the relevance of the mother-daughter relationship stresses the possible role that $\mathrm{X}$ chromosomes could have on successful ageing and on survival in general, which has oriented researchers towards investigating the genetic maternal effects on lifespan through the inheritance of mitochondrial DNA 
(Korpelainen 1999; De Benedictis et al. 1999; Christensen et al. 2001; Fraumene et al. 2003).

However, as Cohen reported in 1964 "familial similarities in life span does not unequivocally imply a genetic factor, for family similarity may result from environmental similarity" (p. 133). Therefore, the relevant association between maternal survival and that of a mother's offspring, and of daughters in particular, cannot be considered to be an exclusively genetic outcome, but interpretation should not ignore the historical social role of the mother. Indeed, mothers have been the primary member of the family devoted to child care and child rearing, cooking, house cleaning and medical care (Van Poppel 2000). In Sardinia they usually maintained family and neighbourhood connections ensuring the support of relatives and friends for the family (Salzman 1997) and transmitted family values, traditions, remedies, customs and lifestyle (Oppo 1990).

Another plausible explanation linked to the central role of mothers in providing family care may be the fact that a possible premature loss of the mother could have a negative effect on survival. As pointed out by Salaris (2010) for the same village, the loss of mother before age 5 had important immediate effects on small children but also proved to have long-term effects, reducing survival at more advanced ages. Consequently, it is also possible to imagine that for older daughters, mother loss implied an additional workload as they most likely had to take care of the family.

\subsection{Family survival resemblance: the role of siblings}

The survival resemblance between siblings is shown to be particularly strong and statistically significant compared to that of parents and it emerges in all analyses presented here. In Villagrande Strisaili we observe that from age 50, having a robust sibship increases the mean age at death by 4.2 years for female and 7.1 years for males compared to frail males.

The average survival of siblings has been operationalised in three different ways in this study and in all the analyses performed the survival of siblings represents a good predictor of individuals' survival, particularly for males.

This result confirms what was found in other studies comparing the survival of siblings of centenarians or of sib-pairs (Bocquet-Appel and Jacobi 1990; Poulain et al. 1998; Perls et al. 2002, 2007; Shoenmaker et al. 2006; Willcox et al. 2006; Blackburn et al. 2004; Mazan and Gagnon 2007; Jarry et al. 2012b). In general, it emerges that having a long-living or a centenarian sibling is a powerful predictor of longer survival and is particularly important for reaching oldest ages. However, in several of the studies cited, researchers also found a positive association for partners, suggesting that the environmental component could also affect longevity.

Siblings share on average 50 per cent of their genetic endowment and among the possible explanations for the positive relationship found between individuals their genetic factors are the most obvious. The fact that siblings are exposed to similar historical and living conditions probably helps to detect more clearly the role of 
genes than in the parents-offspring relationship, where secular improvements in survival could have a distorting effect.

However, in our interpretation we cannot neglect the role of mutual sharing of early environment and socio-economic conditions of the family of origin. The number of factors that individuals share with their siblings is more consistent compared to what they share with their parents. What siblings have in common are genes, but also household characteristics, contextual and environmental variables that are both internal and external to the family, and they experience relevant historical events and/or possible risks of mortality at similar ages. All these factors suggest reflecting on the possible effect of early-life conditions on late survival (Ben-Shlomo and Kuh 2002). In fact, the family should not only be considered as a gene-transmitter, but it also represents the environment that siblings share during childhood and to some extent also throughout their entire lives. The fact that in the population examined the relationship between siblings is particularly relevant for males might suggest that in a society like that of Villagrande Strisaili, which is predominantly pastoral, the dynamics of capital management and accumulation as well as models of co-farming of livestock could be a possible explanation for the strong links established in the past between brothers of a pastoral culture (Murru Corriga 1990).

\subsection{The role of heterogeneity and frailty}

From our results it emerges that to improve the understanding of familial transmission of longevity, research should take into account the role of heterogeneity and that of frailty. Populations are rarely homogenous and individuals demonstrate different levels of susceptibility to mortality (Vaupel et al. 1979). Some persons are more robust than others and conversely some subjects prove to be particularly vulnerable. Moreover, mortality at different ages changes the composition of population at risk as frail individuals are those who are eliminated early and at older ages the remaining survivors are the robust ones (Vaupel and Yashin 2001).

Research on longevity mostly focuses on the robust component of populations, but in a community like that of Villagrande Strisaili where most people are long-lived, it may be difficult to distinguish between groups of individuals according to their survival, all the more so in a context such as that of Sardinia where the population has proved to be genetically highly homogenous (Contu et al. 1998; Lampis et al. 2000).

In opposition to the classic robust-oriented approach, in our analysis the identification of the group of frails among fathers, mothers and siblings made it possible to point out the role that this component also has in population dynamics. Moreover, in Villagrande Strisaili the comparisons of familial survival groups (robust vs frail)—which were identified not with respect to a fixed age but according to the distribution of deaths-showed that the frail component appears to be a more dependable predictor of individual survival than the robust one.

The second important concept related to that of heterogeneity is that of frailty. In the present study frailty has been operationalised at family level as well as its joint 
effect on individual longevity of the survival experiences of all siblings (including the individual in question). Its importance is related to the fact that frailty does not refer to individuals" longevity per se, but to "a set of susceptibilities and risk factors that alter their chances of death at different ages" (Vaupel 1988, 277). Reasoning in terms of predisposition rather than determination of longevity seems more appropriate, as highlighted by a recent critical review of studies on genetic determinants of human longevity (Christensen et al. 2006). The effect of genes, in fact, was shown not to remain stable but rather to determine a certain level of susceptibility to specific diseases and to death. This means that individuals who live longer are assumed to be capable of optimising stress response mechanisms rather than not having negative stimuli (Franceschi et al. 2000). Future developments should further consider the role of frailty as well as examine in greater detail the variability of deaths within families.

\section{Conclusions}

The present contribution focused on the estimation of possible family transmission on longevity, and examined in detail the parent-offspring relationships and those between siblings in a population such as that of Villagrande Strisaili which is characterised by a high level of longevity. Accordingly, the decision to use a relative threshold to identify survival groups proved to be an appropriate strategy since it takes into account the mortality levels of the examined population.

The study aimed to detect the presence of the more robust and more frail components of the population based on the assumption that any episode of marked longevity might be repeated on many individuals within the same family. Indeed, the introduction in the analysis of the frail component proved to be a more informative predictor of individual survival than the robust one.

Among the possible family relationships, the analysis has highlighted the existence in the population of Villagrande Strisaili of a significant mother-daughter relation. However, the most interesting results relate to the role played by age at death of siblings. Having a long-living sibship proves to be a powerful predictor of longer survival and this is particularly important for reaching oldest ages. The relevance of this latter variable emerged in all the analyses performed and was emphasised by the introduction of a weighted measure of sibship survival. The system of weights constructed, albeit crude, enabled us to assign a different importance to family groups according to the detected proportion of most robust members. As a result of our findings it would seem that future research should be devoted to the development of a more reliable system of weights which could take into account familial survival history (including all ages) and additional family characteristics and socio-economic conditions. 


\section{References}

Anatra, B., and G. Puggioni. 1983. Fonti ecclesiastiche per lo studio della popolazione: Inventario dei registri parrocchiali di sette diocesi della Sardegna centro-meridionale. Roma: Comitato italiano per lo studio dei problemi della popolazione.

Assmuth, L. 1997. Women's Work, Women's Worth: Changing Lifecourses in Highland Sardinia. Finnish Anthropological Society.

Austad, S. N. 2006. "Why Women Live Longer Than Men: Sex Differences in Longevity". Gender Medicine 3 (2): 79-92. doi:10 . 1016/S1550-8579(06) 80198- 1.

Aviv, A., J. Shay, K. Christensen, and W. Wright. 2005. "The Longevity Gender Gap: Are Telomeres the Explanation?" Science of Aging Knowledge Environment 2005 (23): pe16. doi:10.1126/sageke.2005.23.pe16.

Beeton, M., and K. Pearson. 1899. "Data for the Problem of Evolution in Man: A First Study of the Inheritance of Longevity and the Selective Death-Rate in Man". Proceedings of the Royal Society of London, II, 65: 290-305. doi:10 . 1098/rspl . 1899.0037.

Beeton, M., and K. Pearson. 1901. "On the Inheritance of the Duration of Life, and on the Intensity of Natural Selection in Man”. Biometrika 1 (1): 50-89. doi:10.2307/2331672.

Ben-Shlomo, Y., and D. Kuh. 2002. "A Life Course Approach to Chronic Disease Epidemiology: Conceptual Models, Empirical Challenges and Interdisciplinary Perspectives". International Journal of Epidemiology 31 (2): 285-293. doi:10 . 1093/ije/31.2.285.

Blackburn, M.-È., R. Bourbeau, and B. Desjardins. 2004. "Hérédité et longévité au Québec ancien”. Cahiers Québécois De Démographie 33 (1): 9-28. doi:10.7202/ Q10850ar.

Blossfeld, H.-P., and G. Rohwer. 2002. Techniques of Event History Modeling: New Approaches to Causal Analysis. New York: Lawrence Erlbaum Associates.

Bocquet-Appel, J.-P., and L. Jakobi. 1990. "Familial Transmission of Longevity". Annals of Human Biology 17 (2): 81-95. doi:10. 1080/03014469000000832.

Caselli, G., and R. M. Lipsi. 2006. "Survival Differences Among the Oldest Old in Sardinia: Who, What, Where, and Why?" Demographic Research 14 (13): 267-294. doi:10.4054/DemRes.2006.14.13.

Caselli, G., L. Pozzi, J. W. Vaupel, L. Deiana, G. Pes, C. Carru, C. Franceschi, and G. Baggio. 2006. "Family Clustering in Sardinian Longevity: A Genealogical Approach". Experimental Gerontology 41 (8): 727-736. doi:10. 1016/j . exger . 2006.05 .009$. 
Christensen, K., T. E. Johnson, and J. W. Vaupel. 2006. "The Quest for Genetic Determinants of Human Longevity: Challenges and Insights". Nature Reviews Genetics 7 (6): 436-448. doi:10.1038/nrg1871.

Christensen, K., K. H. Ørstavik, and J. W. Vaupel. 2001. "The X Chromosome and the Female Survival Advantage: An Example of the Intersection Between Genetics, Epidemiology and Demography". Annals of the New York Academy of Sciences 954 (1): 175-183. doi:10.1111/j.1749-6632 .2001.tb02752 .x.

Cohen, B. H. 1964. "Family Patterns of Mortality and Life Span". The Quarterly Review of Biology 39: 130-81. doi:10 . 1086/404164.

Contu, L., C. Carcassi, S. Orrù, M. Mulargia, M. Arras, R. Boero, S. Gessa, A. L. Loizedda, S. Lai, and L. Floris. 1998. "HLA-B35 Frequency Variations Correlate With Malaria Infection in Sardinia". Tissue Antigens 52 (5): 452-461.

Cournil, A., J. Legay, and F. Schächter. 2000. "Evidence of Sex-Linked Effects on the Inheritance of Human Longevity: A Population-Based Study in the Valserine Valley (French Jura), 18-20th Centuries". Proceedings of the Royal Society of London. Series B: Biological Sciences 267 (1447): 1021-1025. doi:10 . 1098 / rspb. 2000.1105.

De Benedictis, G., G. Rose, G. Carrieri, M. D. Luca, E. Falcone, G. Passarino, M. Bonafé, D. Monti, G. Baggio, S. Bertolini, D. Mari, R. Mattace, and C. Franceschi. 1999. "Mitochondrial DNA Inherited Variants Are Associated With Successful Aging and Longevity in Humans". The FASEB Journal 13 (12): 1532-1536.

Del Panta, L., and R. Rettaroli. 1994. Introduzione Alla Demografia Storica. Roma: Laterza.

Desjardins, B., and H. Charbonneau. 1990. "L'héritabilité de la longévité". Population 45 (3): 603-616.

Fan, J., and R. Li. 2002. "Variable Selection for Cox's Proportional Hazards Model and Frailty Model". Mathematical Reviews number (MathSciNet) MR 1892656, Zentralblatt MATH identifier1012.62106, The Annals of Statistics 30 (1): 74-99. doi:10. 1214/aos/1015362185.

Franceschi, C., L. Motta, S. Valensin, R. Rapisarda, A. Franzone, M. Berardelli, M. Motta, D. Monti, M. Bonafè, L. Ferrucci, L. Deiana, G. M. Pes, C. Carru, M. S. Desole, C. Barbi, G. Sartoni, C. Gemelli, F. Lescai, F. Olivieri, F. Marchegiani, M. Cardelli, L. Cavallone, P. Gueresi, A. Cossarizza, L. Troiano, G. Pini, P. Sansoni, G. Passeri, R. Lisa, L. Spazzafumo, L. Amadio, S. Giunta, R. Stecconi, R. Morresi, C. Viticchi, R. Mattace, G. De Benedictis, and G. Baggio. 2000. "Do Men and Women Follow Different Trajectories to Reach Extreme Longevity? Italian Multicenter Study on Centenarians (IMUSCE)". Aging Clinical and Experimental Research 12 (2): 77-84. 
Fraumene, C., E. Petretto, A. Angius, and M. Pirastu. 2003. "Striking Differentiation of Sub-Populations Within a Genetically Homogeneous Isolate (Ogliastra) in Sardinia as Revealed by mtDNA Analysis". Human Genetics 114 (1): 1-10. doi:10. 1007/s00439-003-1008-3.

Frederiksen, H., M. McGue, B. Jeune, D. Gaist, H. Nybo, A. Skytthe, J. W. Vaupel, and K. Christensen. 2002. "Do Children of Long-Lived Parents Age More Successfully?" Epidemiology (Cambridge, Mass.) 13 (3): 334-339.

Garibotti, G., K. R. Smith, R. A. Kerber, and K. M. Boucher. 2006. "Longevity and Correlated Frailty in Multigenerational Families: Biological Sciences and Medical Sciences". The Journals of Gerontology 61A (12): 1253-1261.

Gavrilov, L. A., and N. S. Gavrilova. 2001. "Biodemographic Study of Familial Determinants of Human Longevity”. Population (English Edition) 13 (1): 197-222.

Gavrilov, L. A., and N. S. Gavrilova. 2011. Early-Life Predictors of Exceptional Longevity in the United States: Why Centenarians Are Different From Their Shorter-Lived Siblings. Presented at Living to 100 Symposium, in Orlando, Florida, January 5-7, 2011.

Gjonça, A., C. Tomassini, and J. W. Vaupel. 1999. Male-Female Differences in Mortality in the Developed World. MPIDR Working Paper WP-1999-009. Rostock: Max-Planck-Institut für demografische Forschung.

Gjonça, E., and P. Zaninotto. 2008. "Blame the Parents? The Association Between Parental Longevity and Successful Ageing". Demographic Research 19 (38): 1435-1450. doi:10.4054/DemRes . 2008.19. 38.

Gudmundsson, H., D. F. Gudbjartsson, M. Frigge, J. R. Gulcher, K. Stefánsson, A. Kong, and H. Gudbjartsson. 2000. "Inheritance of Human Longevity in Iceland". European Journal of Human Genetics 8 (10): 743-749. doi:10.1038/sj . ejhg . 5200527.

Guralnik, J. M., J. L. Balfour, and S. Volpato. 2000. "The Ratio of Older Women to Men: Historical Perspectives and Cross-National Comparisons". Ageing Clinical and Experimental Research 12 (2): 65-76.

Herskind, A. M., M. McGue, N. V. Holm, T. I. A. Sørensen, B. Harvald, and J. W. Vaupel. 1996. "The Heritability of Human Longevity: A Population-Based Study of 2872 Danish Twin Pairs Born 1870-1900”. Human Genetics 97 (3): 319-323. doi:10.1007/BF02185763.

Iachine, I. A., N. V. Holm, J. R. Harris, A. Z. Begun, M. K. Iachina, M. Laitinen, J. Kaprio, and A. I. Yashin. 1998. "How Heritable Is Individual Susceptibility to Death? The Results of an Analysis of Survival Data on Danish, Swedish and Finnish Twins". Twin Research 1 (4): 196-205. doi:10 . 1375 / 136905298320566168.

Jalavisto, E. 1951. "Inheritance of Longevity According to Finnish and Swedish Genealogies". Annales Medicinae Internae Fenniae 40: 263-274. 
Jarry, V., A. Gagnon, and R. Bourbeau. 2012a. "The Family Connection in Exceptional Longevity". Contingencies, the Journal of the American Academy of Actuaries 24 (2): 50-53.

Jarry, V., A. Gagnon, and R. Bourbeau. 2012b. "Survival Advantage of Siblings and Spouses of Centenarians in 20th-Century Quebec". Canadian Studies in Population 39 (3): 67-78.

Kerber, R. A., E. O’Brien, K. R. Smith, and R. M. Cawthon. 2001. "Familial Excess Longevity in Utah Genealogies". The Journals of Gerontology. Series A: Biological Sciences and Medical Sciences 56 (3): B130-B139. doi:10.1093/gerona/56. 3. B130.

Kleinbaum, D. G. 1995. Survival Analysis: A Self-Learning Text. New York: Springer.

Korpelainen, H. 1999. "Genetic Maternal Effects on Human Life Span Through the Inheritance of Mitochondrial DNA". Human Heredity 49 (4): 183-185. doi:10. 1159/000022871.

Lampis, R., L. Morelli, S. De Virgiliis, M. Congia, and F. Cucca. 2000. "The Distribution of HLA Class II Haplotypes Reveals That the Sardinian Population Is Genetically Differentiated From the Other Caucasian Populations". Tissue Antigens 56 (6): 515-521. doi:10.1034/j . 1399-0039.2000.560605 . $\mathrm{x}$.

Liu, Y., M. Zhi, and X. Li. 2011. "Parental Age and Characteristics of the Offspring". Ageing Research Reviews 10 (1): 115-123. doi:10.1016/j .arr.2010.09.004.

Ljunquist, B., S. Berg, J. Lanke, G. E. McClearn, and N. L. Pedersen. 1998. “The Effect of Genetic Factors for Longevity: A Comparison of Identical and Fraternal Twins in the Swedish Twin Registry". The Journals of Gerontology. Series A: Biological Sciences and Medical Sciences 53 (6): M441-6.

Matthijs, K., B. V. d. Putte, and R. Vlietinck. 2002. "The Inheritance of Longevity in a Flemish Village (18th-20th Century)”. European Journal of Population 18 (1): 59-81. doi:10.1023/A: 1013891021803.

Mazan, R., and A.-G. Gagnon. 2007. "Familial and Environmental Influences on Longevity in Historical Quebec". Population (English Edition) 62 (2): 271-291. doi:10.3917/pope.702.0271.

McGue, M., J. W. Vaupel, N. Holm, and B. Harvald. 1993. "Longevity Is Moderately Heritable in a Sample of Danish Twins Born 1870-1880". Journal of Gerontology 48 (6): B237-B244. doi:10 . 1093/geronj/48 . 6. B237.

Mitchell, B. D., W.-C. Hsueh, T. M. King, T. I. Pollin, J. Sorkin, R. Agarwala, A. A. Schäffer, and A. R. Shuldiner. 2001. "Heritability of Life Span in the Old Order Amish". American Journal of Medical Genetics 102 (4): 346-352. doi:10.1002/ajmg. 1483.

Murru Corriga, G. 1990. Dalla Montagna Ai Campidani: Famiglia E Mutamento in Una Comunità Di Pastori. EDES, Editrice Democratica Sarda. http://www . saribs . it/scheda . asp?id=SBS-978-88-SBS-1186-Z\&ver=it. 
Oppo, A. 1990. "Where There's No Woman There's No Home: Profile of the AgroPastorial Family in Nineteenth-Century Sardinia". Journal of Family History 15 (1): 483-502.

Perls, T. T., I. V. Kohler, S. Andersen, E. Schoenhofen, J. Pennington, R. Young, D. Terry, and I. T. Elo. 2007. "Survival of Parents and Siblings of Supercentenarians". The Journals of Gerontology. Series A: Biological Sciences and Medical Sciences 62 (9): 1028-1034.

Perls, T. T., J. Wilmoth, R. Levenson, M. Drinkwater, M. Cohen, H. Bogan, E. Joyce, S. Brewster, L. Kunkel, and A. Puca. 2002. "Life-Long Sustained Mortality Advantage of Siblings of Centenarians". Proceedings of the National Academy of Sciences of the United States of America 99 (12): 8442-8447. doi:10.1073/pnas . 122587599.

Pes, G. M., F. Tolu, M. Poulain, A. Errigo, S. Masala, A. Pietrobelli, N. C. Battistini, and M. Maioli. 2013. "Lifestyle and Nutrition Related to Male Longevity in Sardinia: An Ecological Study". Nutrition, Metabolism and Cardiovascular Diseases 23 (3): 212-219. doi:10.1016/j . numecd.2011.05.004.

Poulain, M., D. Chambre, and M. Foulon. 1998. "L'héritabilité de la longévité: Les centenaires et les autres". Annales De Démographie Historique 2: 37-53.

Poulain, M., G. Pes, and L. Salaris. 2011. "A Population Where Men Live as Long as Women: Villagrande Strisaili, Sardinia". Journal of Aging Research. doi:10.4061/2011/153756.

Poulain, M., G. M. Pes, C. Grasland, C. Carru, L. Ferrucci, G. Baggio, C. Franceschi, and L. Deiana. 2004. "Identification of a Geographic Area Characterized by Extreme Longevity in the Sardinia Island: The AKEA Study". Experimental Gerontology 39 (9): 1423-1429. doi:10.1016/j . exger . 2004 .06.016.

Salaris, L. 2009. Searching for Longevity Determinants: Following Survival of Newborns in a In-Land Village in Sardinia (1866-2006). SIS Best PhD Theses in Statistics and Applications - Demography. Padova: CLEUP.

Salzman, P. C. 1998. The Anthropology of Real Life: Events in Human Experience. Prospect Heights, Ill.: Waveland Press.

Schoenfeld, D. A. 1982. "Partial Residuals for the Proportional Hazards Regression Model”. Biometrika 69 (1): 239-241. doi:10.2307/2335876.

Therneau, T. M., and P. M. Grambsch. 2000. Modeling Survival Data: Extending the Cox Model. New York: Springer.

van Poppel, F. 2000. "Children in One-Parent Families: Survival as an Indicator of the Role of the Parents". Journal of Family History 25 (3): 269-290. doi:10. $1177 / 036319900002500301$.

Vaupel, J. W. 1988. "Inherited Frailty and Longevity". Demography 25 (2): 277-287.

Vaupel, J. W., K. G. Manton, and E. Stallard. 1979. "The Impact of Heterogeneity in Individual Frailty on the Dynamics of Mortality”. Demography 16 (3): 439-454. 
Vaupel, J. W., and A. I. Yashin. 2001. "L'eterogeneità non osservata delle popolazioni”. In Analisi demografica: Nuovi approcci dall'omogeneità all'eterogeneità delle popolazioni, ed. by G. Caselli, J. Vallin, and G. Wunsch, 85-103. Roma: Carocci.

Westendorp, R. G. J., and T. B. L. Kirkwood. 2001. "Maternal and Paternal Lines of Familial Longevity". Population (English Edition) 13 (1): 223-235.

Wienke, A. 2003. Frailty Models. MPIDR Working Paper WP-2003-032. Rostock: Max-Planck-Institut für demografische Forschung.

Willcox, B. J., D. C. Willcox, Q. He, J. D. Curb, and M. Suzuki. 2006. "Siblings of Okinawan Centenarians Share Lifelong Mortality Advantages". The Journals of Gerontology. Series A: Biological Sciences and Medical Sciences 61A (4): $345-354$.

Yates, L. B., L. Djoussé, T. Kurth, J. E. Buring, and J. Gaziano. 2008. "Exceptional Longevity in Men: Modifiable Factors Associated With Survival and Function to Age 90 Years". Archives of Internal Medicine 168 (3): 284-290. doi:10 .1001/ archinternmed.2007.77.

You, D., D. Gu, and Z. Yi. 2010. "Familial Transmission of Human Longevity Among the Oldest-Old in China". Journal of Applied Gerontology 29 (3): 308-332. doi:10.1177/0733464809340154. 